\title{
Stuck Between Mainstreaming and Localism: Views on the Practice of Migrant Integration in a Devolved Policy Framework
}

\author{
Silvia Galandini ${ }^{1} \cdot$ Gareth $_{\text {Mulvey }}{ }^{2}$ - Laurence Lessard-Phillips ${ }^{3}$
}

Published online: 21 September 2018

(C) The Author(s) 2018

\begin{abstract}
In this paper, we explore views on the implementation of migrant integration 'policy' in a setting characterised by devolution, using data collected among local and national policy stakeholders in the UK. More specifically, we focus on localism and mainstreaming, which have recently dominated policy debates and endeavours about integration. Our findings shed new light on the challenges and opportunities of these strategies as they are perceived and experienced by policy stakeholders. In particular, we reflect on the important interplay between different levels of governance and the tensions that arise out of these in a devolved context. Our evidence suggests that the shift from centralised to localised policy action is faced with several challenges. First of all, there is a contradiction between the localism agenda, with the devolution of powers and responsibilities, and the context of austerity. Secondly, there are frictions between levels of governance in the devolved UK context, and particularly on how the implementation of integration at the local level is affected by non-devolved policies. Finally, with regard to mainstreaming the need for a more flexible policy approach that recognises and embraces the complexity and dynamism of the integration process is emphasised.
\end{abstract}

Keywords Integration $\cdot$ Immigration $\cdot$ Policy $\cdot$ Localism $\cdot$ Mainstreaming

Electronic supplementary material The online version of this article (https://doi.org/10.1007/s12134-0180626-5) contains supplementary material, which is available to authorized users.

Laurence Lessard-Phillips

1.lessard-phillips@bham.ac.uk

1 The University of Manchester, Manchester M13 9PL, UK

2 School of Social and Political Sciences, University of Glasgow, Glasgow G12 8QQ, UK

3 Institute for Research into Superdiversity, University of Birmingham, Edgbaston, Birmingham B15 2TT, UK 


\section{Introduction}

The concern with migrant integration ${ }^{1}$ has been at the forefront of policy and academic debates over a considerable number of years. Home Secretary Roy Jenkins referred to integration in 1966 "not as a flattening process of assimilation but as equal opportunity, accompanied by cultural diversity, in an atmosphere of mutual tolerance" (Jenkins 1967, 267). However, in recent years, it has been re-emphasised in policy discourses in the UK. This 'renewed' policy interest in integration is, arguably, linked to the positive trends in migration that the country has experienced, especially since the late 1990s (Vargas-Silva and Markaki 2017), which have significantly changed the ethno-national composition of the population. Migration has become numerically more important but also more diverse, with recent movement of EU migrants joining settled communities from the 'old' and 'newer' Commonwealth countries. In 2011, India, Poland, Pakistan, Ireland, and Germany were the top five countries of birth among immigrants in the UK (Office for National Statistics 2013). The share of ethnic minorities in the population has also increased from 2.9 to $14 \%$ between 1951 and 2011, with most changes happening in the latter part of the period (Cheung and Heath 2007; Jivraj 2012).

At the time of writing this paper, two recent policy reports, in particular, the 'Casey Review' (2016) and the 'Integration not demonisation' report from the All Party Parliamentary Group on Social Integration (2017), highlighted the need to address issues linked to the supposed lack of integration of certain, mostly deprived, groups and communities. The resurgence of this issue comes a few years after the previous UK Governmental foray into the matter: the report from the Department for Communities and Local Government (DCLG) 'Creating the conditions for integration' (DCLG 2012). Taken together, these latest policy documents focus on decentralised and localised approaches to integration. This is in line with the strategy defined in the 2011 Localism Act implemented by the Coalition Government that describes localism as a "series of measures with the potential to achieve a substantial and lasting shift in power away from central government and towards local people" (DCLG 2011, 1). Furthermore, these policy documents embed migrant integration in a context of austerity - reduced public spending - and mainstreaming in "an effort to reach people with a migration background through social programming and policies that also target the general population" (Collett and Petrovic 2014, 1). This approach within integration policy has gained momentum in recent years, especially in the UK-although with a stronger focus on ethnic diversity (Scholten et al. 2017). Of course, mainstreaming and localism are often context specific and contested, and indeed vary across nation states (see Ambrosini and Boccagni 2015). While some states use these terms to signify a move away from multiculturalism, at the local level, they play out very differently. The 'de-ethnicized approach' (Ibid, 42), while allowing for the targeting of some groups, such as single parents, does not allow for the targeting of programmes at ethnic minorities. Nevertheless, Ambrosini and Boccagni point to what we might refer to as an implementation gap that the national rhetoric of de-ethnicisation is often followed by continuation with previous

\footnotetext{
${ }^{1}$ While we do not uncritically accept the concept of integration, we use it for pragmatic reasons. It allows us to engage with policy debates and to interrogate the concept with the interviewees. Nevertheless, we agree with arguments about integration being too focussed on individuals and not enough on structures, and that therefore non-integration, however that is measured, is seen by policy as being due to individual action or inaction rather than other factors.
} 
practice, though in a less visible form, often through the presentation of these practices meeting general rather than specific needs.

Despite the relevance and influence of these endeavours, there is no clearly articulated UK-wide, national policy with regard to migrant integration (Spencer 2011; Saggar and Somerville 2012; Ali and Gidley 2014). Moreover, the fact that migrant integration, in many cases, is considered a devolved issue despite being intrinsically linked to the non-devolved policy area of immigration policy has caused tensions between different levels of government (Mulvey 2018). For example, the complex implementation of asylum policy (which involves different levels of government but is essentially an area of policy that is reserved to the UK Government) and the issue of refugee integration (primarily devolved through social policy) have tended to be looked at separately by UK policy-makers (Mulvey 2015). Given recent and upcoming changes to the politics of migration, especially in the wake of the vote to leave the European Union, the 'refugee crisis', and the question of Scotland's future, debates about integration and its implementation are likely to increase rather than disappear. It is therefore important to gather evidence on how the current policy debates and approaches are impacting on the implementation of migrant integration.

We contribute to this debate by exploring how the strategies of localism and mainstreaming that have increasingly dominated debates on migrant integration are perceived and experienced by local and national policy actors. We use data collected in 2015 via semi-structured interviews with local (Manchester/Glasgow) and national (UK/ England/Scotland) policy stakeholders, i.e. individuals in local government and the Third Sector whose professional roles focus on issues related to ethnic and immigrant communities. Our findings shed light on the opportunities and challenges that localism and mainstreaming pose in a devolved institutional setting. In particular, we reflect on the extent to which these policy approaches are seen as effective and feasible ways of addressing integration, and the ways in which the co-existence of different levels of government can be both valuable and, at times, detrimental to integration in practice.

\section{A Short History of UK Migration Policies}

After the Second World War, labour shortages in the UK led to the search for 'workers', usually seen as temporary by the UK Government (see for example Hansen 2000). Most labour was to be found in the colonies of the British Empire. From the beginning of non-white colonial migration, there were concerns and complaints about supposed cultural differences and significant experiences of racism in employment and housing, just to name two areas of policy (see, for example, Solomos 1989). From the 1960s, a system was created that essentially stripped British passport holders from the crumbling empire of their right to come to the UK. This was the external plank of a dual immigration policy and practice, the strict limitation of numbers of arrivals. The internal plank was to institute race relations policies to outlaw discrimination. Nevertheless, restrictions on access to the UK were not evenly applied, with notions such as patriality planting racial discrimination in the heart of the immigration system, according to Joppke as a "revenge of empire" (Joppke 1998, 134). Internally, race relations policy did not end racial discrimination, with an 'ethnic penalty' still evident (Heath et al. 2000). 
This practice essentially existed right up until the election of the New Labour Government in 1997, when there was a shift to a more 'liberal' migration practiceat least for wanted 'labour' migrants. Restriction was aimed primarily at unwanted asylum seekers, as assumptions about legitimacy regarding claims for asylum became a crucial part of the immigration system. This has led over many years to claims of the Home Office operating a 'culture of disbelief' (Anderson et al., 2014). Access to rights were restricted and increasingly stratified for asylum seekers and from 2006 also for low-skilled non-EU migrants.

Policy has continued to create wanted and unwanted migrants, some subject to stringent controls, some to more relaxed controls, and some to no controls. EU citizens, the wealthy and or/entrepreneurs, and intra-company transfers have had no or limited controls placed on them, while migrants from the developing world, or the global south, have few migration options open to them (Beaverstock 2005). Low-skilled migration from outside the EU is all but banned, higher skilled migration from the global south (with certain exceptions such as healthcare and IT workers) comes with familial restrictions, and the ability of refugees to come to the UK to claim such status has been severely curtailed as a result of 20 years of restrictive policy and practice (Anderson 2010; Ruhs and Anderson 2010). The recent vote to leave the European Union, with a campaign almost entirely based on 'taking back control' of migration, has created another series of problems, especially with regard to the position of EU nationals in the UK. This will undoubtedly lead to new migration policy in the near future. As we write, these debates are ongoing.

\section{Implementing Policy and Integration in a Devolved Setting}

The UK has what is described as asymmetric devolution (see for example Curtice 2006). Devolved authorities in Scotland, Wales, and Northern Ireland have policy competences over different aspects of policy, while fiscal relations are organised through the Barnett Formula, i.e. taxes from all four countries go to Westminster and a certain amount is then sent back, calculated by population share and policy competencies (Midwinter 1999). The 1999 Scotland Act, and its successors, dictates that all policy areas not explicitly reserved to Westminster are devolved to the Scottish parliament, an important issue given the impending 'return' of powers as a result of Brexit. Broadly speaking, immigration policy, who is allowed into the country, is reserved to the UK Government but 'immigrant' policy, what happens once they arrive, is largely devolved to the Scottish Government. That said, the transversal policy area of integration in the UK covers both. For example, areas such as immigration policy, employment and welfare, national security, citizenship and naturalisation, and foreign affairs are all reserved while housing, education, health, community planning, neighbourhood policy, policing, and social work are all devolved. Successive Scottish Governments (and the precursor Scottish Executive) have lobbied for control over some aspects of immigration policy, most notably the post-study work visa (Scottish Government 2016), but to no avail. Thus, it is in other areas of social policy that have an impact on integration such as housing, health, and education that differences can emerge. We have seen a diverging approach in many social policies between Holyrood and Westminster (and also in different ways in Wales and Northern Ireland) since the 
beginning of devolution (Birrell 2009). A different emphasis has been evident in terms of both policy and underlying philosophy where the UK Government has moved in the direction of stratifying rights and access to social goods, while the Scottish Government appears to favour a form of constrained universalism (Mulvey 2018). The UK Government has emphasised migrants as more or less useful units of labour and in terms of the welfare state has stratified rights and pushed a conception of individual responsibility (Morris 2002), a return to the 1960s consensus that the presence of migrants is essentially what causes problems.

Thus, integration policy is explicitly linked to immigration, as the 'solution' to integration problems is seen as revolving around letting fewer people come to the UK-a key component of the Brexit 'debate' - alongside making life more difficult for those who do come, through restricting access to social goods. There is little to say about Westminster or Holyrood policy on the integration of non-refugee migrants, apart from the very limited resources available through the Migration Impacts Fund, which was set up by Gordon Brown to relieve the pressure of immigration on local services but ended by the Coalition Government in 2010 . Additionally, the hostile climate created by policy-makers and the media means that all aspects of integration are made more difficult. Indeed, the UK Government created a 'Hostile Environment Working Group' (see Balch 2016) with that specific aim "(see, e.g., the recent Windrush scandal as a prime example of the consequence of the Hostile Environment strategy). Taking as a whole, therefore, it appears fair to suggest that integration (when it happens and however it is measured) currently happens despite rather than because of UK Government policy. In contrast, the Scottish Government has maintained some focus on structures that help or hinder integration alongside a degree of universalism in terms of access to social goods (Mooney and Williams 2006). However, this takes place within a system that solely uses an economic rationale for support for migration (see Law and Mooney (2012) on the SNP and competitive nationalism).

One important area of policy divergence is refugee integration. The UK Government approach since the early 1990s has been one of differentiating between refugees and asylum seekers, with small numbers of resettled refugees wanted, or at least tolerated, and asylum seekers unwanted (Squire 2009). The distinction treats those in the asylum system differently from recognised refugees, with their rights and access to goods and services increasingly thwarted. Policy interventions, where they have existed, have been aimed solely at those who have had their claims for refugee status recognised (Spencer 2011). Scotland has always taken a symbolically different approach from that of the UK Government on refugee matters. Since the establishment of the Scottish Parliament in 1999, all administrations have operated on the basis that, where they have powers to do so, integration should begin the day an asylum seeker arrives in Scotland under the Home Office dispersal scheme (Scottish Government 2013). In addition, some of the restrictions in access to social rights instituted by the UK Government have not been applied in Scotland, so, for example, access to free ESOL (English for Speakers of Other Languages) for those in the asylum system and access to further education, although restricted, remain (Scottish Government 2013).

Devolution is not simply concerned with the responsibilities that have moved from Westminster to the devolved administrations. Of crucial importance for this article is the devolution of responsibilities to local governments. In this case, there seems to be more convergence than divergence between the two countries. The commitment of the UK Government to promote locally rather than centrally led action was clearly stated in 
the DCLG document outlining the conditions for integration in England (DCLG 2012, 2), and formally implemented in England and Wales through the 2011 Localism Act (HOC 2011). This devolved more responsibilities to the local level, increasingly to directly elected mayors, yet without necessarily transferring any additional powers or financial resources to Local Authorities (LAs) (Bentley and Pugalis 2013; Clarke and Cochrane 2013) — which could be seen as a devolution of penury (Mitchell 1998). The Scottish Government does similarly in the case of Scottish LAs with, for example, much of the implementation concerning the Refugee Integration Strategy, 'New Scots', being the responsibility of local government, but with no money tied to it. The Community Empowerment Act also appears to give people the right but not the power to do things locally.

With regard to mainstreaming, the trends have also gone generally in the same direction in Scotland and in the rest of the UK. Issues of race equality, race relations, and social inclusion in the UK primarily focus on ethnicity rather than immigration and have been kept separate from migration policies, although intrinsically linked (Collett and Petrovic 2014). The increased popularity of the community cohesion agenda in the early 2000s has coincided with a strong push for policies promoting social mixing across ethnic and religious boundaries and tackling issues affecting the whole of society, such as poverty and social exclusion (Scholten et al. 2017), though in the context of welfare state retrenchment, this push has very fragile moorings. The Scottish Government has also been moving inexorably in this direction, whether through the public sector equality duty or the Equality Outcomes and Mainstreaming Report work. Yet, there is still targeted funding provided for organisations such as the Scottish Refugee Council and Black and Ethnic Minority Infrastructure Scotland.

\section{Data and Methods}

As mentioned, the paper is based on primary evidence from semi-structured elite interviews (Kvale and Brinkmann 2008, 147) conducted with policy stakeholders (Lessard-Phillips 2017). These include (1) local policy-makers-i.e. councillors and public officials - and (2) national and local representative of charities and community organisations (Third Sector) as well as think tanks working on issues related to ethnic and migrant minorities, including refugees and asylum seekers. The national level refers to both the UK/England and Scotland, while locally the fieldwork took place in Greater Manchester and Glasgow. A total of 24 interviews were carried out between January and September 2015. More specifically, we conducted 9 interviews with local policy-makers and stakeholders in Greater Manchester and 5 in Glasgow, as well as interviews with 6 national stakeholders in the UK/England and 4 in Scotland. ${ }^{2}$

The reason to conduct the fieldwork in Greater Manchester and Glasgow was twofold. First of all, both cities have experienced increasing levels of immigration and ethnic diversity. Although Manchester has a slightly more longstanding history of diverse migration to the area, Glasgow's migration was dominated first by Irish and Commonwealth migration from the Indian sub-continent. It is only since 2001 that more diverse migratory patterns have existed in Glasgow. In particular, the two cities are important sites of dispersal

\footnotetext{
${ }^{2}$ Ethical approval for the project was granted by the ethics committee of the University of Manchester (Ref 14267) and the University of Birmingham (Ref ERN_16-0726).
} 
for asylum seekers and of migration for a growing number of EU migrants and international students (Ali and Gidley 2014). We therefore expected integration to be a relevant and current policy issue for both cities. Secondly, Manchester and Glasgow have become relevant localities in England and Scotland, respectively, due to the minted position as the 'Northern powerhouse' for Manchester and the largest and growing population and political role in Scotland for Glasgow (Katwala et al. 2017).

The study adopted a non-probability purposive sampling strategy: interviewees were recruited on the basis of their specific knowledge and expertise in issues related to various aspects of ethnic minority and migrant integration (Jupp 2006). Prospective interviewees were initially identified through three main channels: (1) an online search; (2) direct contacts made with policy stakeholders established by the research team during policy and public engagement events; (3) advice from researchers who had already worked with policy-makers and stakeholders; and (4) suggestions from interviewees themselves (i.e. snowball sampling).

Interviews were conducted primarily face-to-face, although two interviews were conducted by phone. All interviews focused on four areas of interest: how integration is defined and what are its dimensions; what can be done to achieve integration; and who should be responsible for this process (see supplementary documentation for details). The interviews were transcribed verbatim and analysed in Nvivo 10 following a thematic analysis approach (Braun and Clarke 2006). A set of initial codes were generated, reviewed, and refined on the basis of the interviews' content. We inductively captured themes around localism and mainstreaming as they emerged directly from the interviews.

\section{Findings}

\section{Integration Happens Locally}

We found widespread support for localism and some resistance to 'top-down' approaches to integration among the policy stakeholders interviewed. LAs were generally viewed as the bodies that do and should play a prominent role in leading the implementation of integration policies and initiatives. They are the ones that have practical and direct experience of dealing with the effects of new migration, increasing levels of ethnic diversity and the provision of statutory services to existing and new communities. Localism was then perceived as the channel through which local governments along with other policy actors (i.e. Third Sector) and local communities can work together to devise appropriate and effective measures to pursue integration by adapting to the specific issues and dynamics of each locality:

You've got a very [name of local authority] problem and a very [name of local authority] solution to it, and I don't think that necessarily translates onto the national stage because it's not the same sort of problem. (National, UK, February 2015)

And some of those things absolutely are local. I think the top down level does not work. It has to happen from the local level. So, devolving powers to Local 
Authorities, letting Local Authorities be innovative and working with communities. But devolving power to local communities, working with local communities, saying, okay, what would work in this community? (Local, England, August 2015)

The various accounts collected (particularly at the local level) provided numerous practical examples of actions developed and implemented at the local level for a wide array of issues spanning from, among others, decisions about the settlement of asylum seekers, the delivery of ESOL classes, managing community relations at the neighbourhood level and, more generally, the provision of statutory services (e.g. health, education). These accounts shed important light on how integration happens and is managed locally. In some cases, interviewees further reinforced their support for localism by describing integration as a process that involves cities and communities rather than individuals, hence emphasising the role played by localities and local contexts in this process:

I think of integration now, not as something that involves these groups and people interacting and moving towards a different and a better place, but as something that happens to and in places. And it's not the people that get integrated it's the places that become integrated places. Cities in particular I am thinking of. But obviously, one should be able to extend this to places, localities that are not cities. (...) And, the definition of integration with which I now feel most comfortable with is that we should think about places integrating, not people integrating (National, UK, January 2015)

Others also stressed the importance of developing even more localised strategies where communities and groups spontaneously organised by residents initiate actions for which LAs simply provide the necessary tools and resources in a virtuous process of community empowerment (i.e. 'community asset-based approach'). Overall, the 'bottom-up' approach going from local to national governments (but also from communities to local governments) was seen as a channel through which more effective and realistic actions can be taken from those directly exposed to the challenges and opportunities of integration rather than these actions being imposed from the top, hence generating a more positive impact.

\section{The Bumpy Road to Localism}

Despite this generally strong support for a 'bottom-up' or more locally autonomous approach to integration, issues and challenges of the current policy strategies focussing on localism were widely pointed out. The role of national governments (both UK and Scottish) was described as crucial even in a policy framework that focuses on localism, and criticisms were raised about extreme applications of localism and devolution in the current national policy framework. These calls for a stronger contribution from and involvement of national governments among interviewees were based on two main arguments.

First of all, national policy frameworks determine the level of financial support to LAs in relevant areas of integration. Lack of adequate financial resources was one of 
the main challenges highlighted by policy stakeholders at the local and national level, in England and Scotland equally with regard to addressing and pursuing integration. Looking at the two cities that we focus on in this paper, Glasgow City Council has increased responsibilities but its budget was cut by $£ 53 \mathrm{~m}$ for 2017 alone (£250m in total between 2010 and 2016). For most of that period, they were also prohibited from raising Council Tax. In the case of the ten LAs that make up Greater Manchester, they have collectively seen cuts of $£ 1$.7bn between 2010 and 2016. This means that LAs are stretched and in many cases struggle to deal with their increased responsibilities regarding policy domains that directly impact on integration. This not only makes it very difficult for LAs to operate beyond the provision of statutory services (i.e. their main duty) but it also shifts the attention of local policy-makers and service providers to more pressing issues and challenges. For instance, some explained that increasing cuts to public spending decided centrally have led councils to focus on implementing measures to "deliver services more effectively" (Local, Scotland, September 2015) and to focus on the most urgent issues, such as poverty. This inevitably leads to shorttermism and a fire-fighting approach to service delivery rather than a more strategic approach (Christie 2011). It has also affected the Third Sector and local communities in general as LAs tend to rely more on "what can people do to help themselves, what can community groups do to help, help other residents" (Local, England, April 2015), rather than being able to provide services directly. Representatives of Third Sector organisations, especially smaller grassroots community organisations, pointed out the difficulties of keeping up with this increasing demand without sufficient financial resources:

There is a change in attitude of the local councils and organisations to work more, but there isn't enough money and resources to go around to do the work. So individuals have made the changes, but there isn't enough support in terms of funding and other resources from central government for the staff members to use their experience and say, okay, I would like to do this, this and this with this pot of money. But I must add that councils and other organisations are definitely trying to reach out and find the genuine need within communities and give funding to them. (Local, England, January 2015)

For some, the support of the UK government for localism is in stark contrast with the decreasing financial resource centrally allocated to LAs. For this reason, policy frameworks at the national level are seen as a channel through which central Scottish and UK Governments not only define general policy but also, and primarily, engage more resources to support local communities if a certain area of intervention is identified as important. This is the case, for example, of ESOL provision at the local level. If this is identified as a priority by the government, then a national statement as well as increased support for this policy area should be expected so that ESOL provision at the local level can be guaranteed. Therefore, national policy frameworks could benefit integration if they represent a political commitment from national government both in terms of policy statements and financial resources, rather than simply transferring responsibilities from central to local governments without providing the necessary financial support - once more the devolution of penury. Indeed, the context of austerity occurring at the same time as these moves towards localism, at least rhetorically, are 
suggestive of an altogether different aim, one that has at least in part an ambition to erase cultural difference while simultaneously absolving the central state from responsibility. That is, it seems ambitious to say the least to expect local actors to be able to devise actions that meet the needs of diverse localities at a time when their budgets are being slashed.

The second reason to support more national engagement, rather than a simple devolution of power to localities, concerned the provision of practical and political guidance. Integration is a transversal policy area and, as described above, has a strong localised nature. However, national guidance would help build a more cohesive scene in such a fragmented field:

There's no real coherence to it. It's done very reactively. That has a big impact on the public confidence point, which is critical, I think, for integration, and it means that public services struggle and you have this situation of flare-ups in communities. So I think, yeah, that's what you lose when you don't have that sort of national overview. (National, UK, March 2015)

What seems to be crucial in defining the relationship between local and national levels of governance is to find and maintain 'the right balance'. In particular, there were concerns about national policy frameworks restricting the action of local governments and hence becoming a negative 'top-down' imposition of policy priorities but also an ineffective one-size-fits-all approach that might not work in specific local contexts:

I think that sort of centralised top down we have a British definition of integration and you're all going to oblige and we'll monitor you, probably isn't the most helpful. (National, UK, March 2015)

One solution often suggested by interviewees to possibly overcome the dangers of a topdown approach is the multiagency or partnership approach, which is already implemented in some instances. Regardless of this multiagency approach being applied to local and national governments or local actors, one issue that was generally mentioned is the provision of the financial and other strategic resources that would be needed for these partnerships to produce positive outcomes both at the national and local level.

\section{The Push Towards Localism: the Impact of Non-Devolved Policies}

There is another factor that seems to pose serious challenges to localism (as currently implemented) and the effective devolution of powers when it comes to pursuing integration and balance between local and national levels of government. This is the strong impact that decisions made by the UK Government in non-devolved policy areas have on the ability of LAs and local actors to actually address and shape integration locally. While this has been examined with regard to the effects of the asylum process on devolved social policy (Mulvey 2018), it is also relevant to other forms of migration (e.g. family reunion, minimum income, EU migrants). This issue emerged quite strongly from interviews conducted both in England and Scotland, with the latter being particularly sensitive to the limitation that the devolution 'settlement' still presents. Two policy areas were identified as particularly problematic. 
Firstly, interviewees mentioned immigration policies (i.e. who is allowed to come into the country and under what conditions), which are entirely defined and controlled by the UK Government. These have become increasingly restrictive and sit alongside a series of policy measures aimed at dissuading people from coming to the UK. This restriction concerns acquisition of citizenship, family reunion, and requirements to obtain indefinite leave to remain or work visas, but also migrants' access to social rights (for both EU and non-EU migrants), which show some variation between Scotland and England (as discussed in the "Implementing Policy and Integration in a Devolved Setting" section). In this regard, there was first of all the suggestion that integration and immigration issues and policies are closely and inevitably linked

(...) the whole immigration policy field is constantly about integration. There is not really an aspect of it, even questions of border controls or rules on family reunification, or asylum determination procedures, or the resolution of particular cases by the higher Courts in the UK, or Strasbourg or whatever, none of these issues are really isolated from the question of integration. (National, UK, January 2015)

This is primarily because the acquisition of citizenship or a more stable immigration status (through permanent residence or family reunification) significantly impacts on the ability of individuals to settle and acquire rights and hence affect the lives and fabric of local communities. Tougher immigration rules established nationally were described as contrasting with the need for more stability for individuals and communities, but also for people to be able to start a process of integration into the receiving society:

The other thing we have found is that people seem to favour settlement over transitory forms of migration, which I think there's a real tension with broader immigration policy which is sort of, to some extent, incentivising people to stay here temporarily. (Local, England, April 2015)

I think access to citizenship is an important one (...) not just citizenship, but permanent residence as well. We've seen the rules getting progressively more difficult for people to move towards permanent residence in the UK, more and more people are stuck on temporary residence and then the insecurity that that gives about the future and the ability to plan for the future have really undermined integration of those communities. (National, UK, January 2015)

Tougher rules regarding migrants and access to public support and welfare benefits were also mentioned as one of the sources of destitution and hence of the need for further actions at the local level to support those who do become destitute:

So the central government can say we're restricting migrants access to benefits, therefore we are discouraging them from coming here, whereas our experience is actually most migrants do generally want to work, people aren't here ... because they want to get benefits. But if the central government goal, policies make local people destitute, in practice, (...) under the government policies they've got no recourse to public funds so they'd been made destitute, actually we've got 
responsibilities under the children's act or human rights legislation which say actually we need to, we need to prevent these children being destitute. (Local, England, April 2015)

In this case, legislation about local government responsibilities alongside many social policy fields means that UK policy is merely putting more financial strains on already tight local budgets, due to the fact that LAs have both a statutory and moral responsibility to those living in their jurisdiction.

The topic of devolved versus exclusive policy areas is particularly relevant in the case of Scotland, where the inability to influence the immigration policies implemented by the UK government is problematic (Hepburn 2015). This was felt by some as an important limitation to the ability of Scotland to have a coherent approach:

You know, with a devolved situation where we had no control over immigration, it's even more difficult. (National, Scotland, May 2015)

I think that this government stance on immigration is really going to be tough for a lot of families and a lot of individuals that are here now, and how that reflects the general feeling of communities welcoming newcomers and new people into Scottish society and that people are now forgetting what, you know, where Scotland comes from and how mixed we are here. (Local, Scotland, July 2015)

Besides immigration policies, a second area of conflict between UK policies and impact on localities highlighted by interviewees is the issue of asylum seekers dispersal, which is particularly relevant in localities like Manchester and Glasgow. Both of these LAs opted to take part in asylum dispersal and are therefore areas where large numbers of asylum seekers have been located-around $10 \%$ of the annual UK total in the case of Glasgow (Stewart and Shaffer 2015). Again, a policy that is exclusively decided nationally, but is carried out by LAs, has a crucial impact on local communities, their composition, and the ability of local policy stakeholders to deal with these changes effectively. Challenges were primarily linked to where asylum seekers are initially housed (often in areas that have scarce resources to welcome them and accommodate their needs), but also with the difficulty, once again, to encourage long-term settlement and stability when the process of seeking asylum is so uncertain and centrally controlled and where a 'culture of disbelief' exists. In the words of one local interviewee:

Sometimes people move to London and it's a shame to say bye, but it should really be that if someone moves here and you support them through the asylum system and they gain refugee status, that they're encouraged to stay and to be part of the community that they want to settle in, and not be forced then again to move on and to find other places that support them, because they can't - they've gone through the process here, but then the end result is there's nothing for them at the end. (Local, Scotland, July 2015)

While individuals do move after being recognised as refugees, the vast majority do not (Stewart and Shaffer 2015). What is more, integration can be affected by non-refugee policy practice where, for example, refugees in England who want to move LA area 
cannot access social housing in their desired location due to not having a 'local connection'. In Scotland, no such connection is required.

\section{Mainstreaming: Integration for All?}

The other important question we explore with regard to the approach to integration is whether integration should be pursued through mainstreaming or a more targeted approach, i.e. whether it should be incorporated into policies targeting the general population, with migrants being reached through those channels, or whether it should be a standalone policy. The policy context, especially in England, has increasingly supported mainstreaming and progressively abandoned financial and political support for more targeted, needs-based programmes, with Scotland maintaining a stronger position in support of targeted actions to support migrant integration (Ali and Gidley 2014). The data appear to confirm these patterns, with interviewees in some cases suggesting that lower level of financial resources have been provided by central government to implement actions targeting the needs of specific ethnic or migrant groups.

However, the discussion about whether mainstreaming is beneficial and should be pursued is polarised and complex. Some emphasised the different needs of migrants, given their specific position is society (i.e. temporary immigration status and limited access to rights) and different 'starting points' and challenges compared to settled ethnic minorities. This would differentiate them from second- or third-generation minorities and hence suggest a more targeted policy approach to integration:

I think policy on integration always ought to reflect on, respond to the specific nature of the population you are talking about. It's sensible you've got to take that into account. You can't abstract from it. And certainly, as we all know, it's nonsense to treat migrants as a monolith and we also know that the experience of second generations varies enormously. All of that one ought to better take account of, very objectively and systematically. (National, UK, January 2015)

This is reflected in practical examples given, especially by local stakeholders, about actions that were taken with regard to migrant groups or newcomers (versus more settled minority communities). Targeted actions and strategies in these instances were deemed to be more effective to address very specific needs and challenges that these groups faced. In particular, LAs and service providers would value and adopt targeted approaches to make their services equally accessible to any member of the local community, including newcomers with specific cultural and linguistic needs, for example. The case of stakeholders working with asylum seekers and refugees also pointed to the benefits of the tailored nature of their work (see Ambrosini and Boccagni 2015 for further examples of local practice).

Nonetheless, in some instances, interviewees expressed doubts about the effectiveness of targeted approaches to integration and supported mainstreaming and a more generalised interest in reducing inequalities and social exclusion, issues that are shared across societal groups. In this perspective, it was suggested that the strategies developed initially to tackle issues related to newcomers (and specific groups of migrants) could be applied to the wider society as they address challenges that are widespread, 
particularly when it comes to equality of opportunities and social inclusion, as explained in this quote by a national stakeholder while discussing the applicability of frameworks of migrant integration:

I think it's applicable for everyone; not just migrants. I think some things can change. Obviously, if you're a migrant, you have different rights. So if you're looking at the foundation, then obviously it's a different starting point. But, interestingly, I think if you're taking it from a human rights point of view, that's applicable to everyone. (National, Scotland, September 2015)

In some instances, this mainstreaming view is linked to not wanting to 'single out' migrants or ethnic minorities and put a very specific onus on them rather than emphasising that integration is something that relates to the whole society, including the white British-born majority, which also plays a role in the integration process:

(...) need crosses all different kinds of divides and I don't think it's necessarily specific to ethnic minorities or a given ethnic minority. It's more about what are the cracks that people can fall through and how does the state ensure that there is, ideally, the net very, very close or that those holes are plugged so they don't fall through them. (...) Yeah, and whether targeting actually, in certain areas, causes more problems. Not necessarily harm, because if you want to integrate, if that's the overall aim, yes, you need to make sure that people are supported to succeed and to do well, but not at the expense of them feeling like their ethnicity is some sort of cross they have to bear and it's a real problem. So sometimes it's got to be a little bit more subtle or latent than that. (National, UK, February 2015)

If you look at the issue of how we handle immigration fairly, if you look at the questions of what is successful integration in a multi-ethnic, multi-faith society, if you look at faith issues across faiths, if you think that the subject of those debates is migrants or minorities or Muslims then you're putting all of the pressure to sort it out on a group without the power to do it. And they're all questions about what the broader society feels it is and whether those groups have equal status and access, equal responsibility within it. So we thought that all of these questions in fact belong to the majority society. (National, UK, March 2015)

It appears that at the core of the debate about mainstreaming is the question of who integration relates to: newcomers, ethnic minorities, whole communities, or, as previously argued, places? The debate about the practical implementation of integration seems to move back and forth on this complex issue. It emphasises a clear dichotomy between first-generation migrants and their children when highlighting that these groups have different needs and should be targeted by different policies. At the same time, however, this bright boundary remains blurred not only because 'migrant' and 'ethnic minority' are not mutually exclusive categories but also given the traditional "societal reluctance to frame minorities as migrants" (Ali and Gidley 2014, 1) who are being asked to 'integrate' into the same society they were born in (see Miles (1993) for a critique of the concept of integration for these very reasons). Moreover, great complexity exists within migrant and ethnic minority groups along other demographic 
and socio-economic lines (e.g. gender, age, social class), and this would point towards a different range of targeted policies.

Overall, for these reasons, the debate on mainstreaming seems to be caught in a dilemma. Migrants appear to suffer from specific disadvantages and face different challenges compared not only to the majority mainstream but also settled ethnic minorities. Integration practice would therefore benefit from shifting away from mainstreaming and paying more specific attention to these groups. Nonetheless, the growing socio-economic disparities and social exclusion to be tackled with reduced financial resources and the danger of applying the term integration to settled minorities as well as putting the onus of integration on migrants seem to play an important role in supporting the idea and practice of mainstreaming. Moreover, if it is indeed places rather than people who become integrated then perhaps place-based approaches still have a role.

\section{Conclusion}

Cities and localities are where immigration has long-term impacts and where integration practice 'plays out' (Crul and Schneider 2010). This finds supports among the local and national policy stakeholders we interviewed. Nonetheless, our evidence suggests that the shift from centralised to localised policy action is faced with several challenges. First of all, there is a contradiction between the localism agenda, with its devolution of powers and responsibilities, and the context of austerity. Local policy actors cannot continue to do more with less resource and devolving more penury has a negative impact upon the places and communities where integration happens. Furthermore, findings shed light on the frictions between levels of governance in the devolved UK context, and particularly on how the implementation of integration at the local level is affected by non-devolved policies. For instance, we highlighted the difficulty of facilitating integration in local communities while UK-wide immigration policies promote short-term stays and long-term instability and political debates focus on harsh anti-immigration rhetoric - which received further legitimisation during the Brexit 'debates'. The championing of localism can also conflict with a national policy discourse and in some cases practice, which suggests the need for immigrants to integrate into the nation and its values rather than the locality in which they live (see Gebhardt (2016) for a similar argument in European localities). These mixed messages can be difficult to traverse. Despite the challenge of bringing together national policies and local actions, our data show the importance of having a national framework providing adequate financial resources, but also strategic and political guidance to local policy actors and communities to help them develop positive actions. The UK government can play a strategic, positive, role and should avoid steering away from involvement.

With regard to mainstreaming - the second core element addressed in the paperthe evidence we presented emphasises once again the need for a more flexible policy approach that recognises and embraces the complexity and dynamism of the integration process. This is not a case of straightforward universalism. On one side, it is inevitable for policy-makers engaged with issues of poverty and social exclusion that affect the whole population, beyond ethnic origins or immigration status. On the other side, 
however, it is necessary to remember that debates on integration involve very diverse individuals and communities with specific needs and priorities. Clear boundaries and policy responses are certainly difficult to identify, but a more targeted approach to these processes has at times proved to be more effective and this 'best practice' should not be lost but shared and used as basis for more positive actions. Given the changes ahead, especially with regard to Brexit negotiations, bringing different levels of governance to work together in a cohesive manner to create policy tools able to tackle complexity without leaving anyone behind will be a great challenge ahead.

Funding Information The authors gratefully acknowledge the support of the Economic and Social Research Council (grant numbers ES/K009206/1-2) and wish to thank research participants and reviewers for their input.

Open Access This article is distributed under the terms of the Creative Commons Attribution 4.0 International License (http://creativecommons.org/licenses/by/4.0/), which permits unrestricted use, distribution, and reproduction in any medium, provided you give appropriate credit to the original author(s) and the source, provide a link to the Creative Commons license, and indicate if changes were made.

\section{References}

Ali, S., \& Gidley, B. (2014). Advancing outcomes for all minorities: experiences of mainstreaming immigrant integration policy in the United Kingdom. Washington, DC: Migration Policy Institute Europe http://migrationpolicy.org/research/advancing-outcomes-all-minorities-experiences-mainstreamingunited-kingdom. Accessed 01.09.2015.

All Party Parliamentary Group on Social Integration. (2017). Integration not demonisation: the final report of the All-Party Parliamentary Group on Social Integration's inquiry into the integration of immigrants. London: APPG Social Integration. http://d3n8a8pro7vhmx.cloudfront.net/themes/570513f1b504f500 db000001/attachments/original/1504379228/TC0016_AAPG_Integration_not_Demonisation_Report. pdf?1504379228. Accessed 31 Jan 2018.

Ambrosini, M., \& Boccagni, P. (2015). Urban multiculturalism beyond the 'backlash': new discourses and different practices in immigrant policies across European cities. Journal of Intercultural Studies, 36(1), 35-53.

Anderson, B. (2010). Migration, immigration controls and the fashioning of precarious workers. Work, Employment and Society, 24(2), 300-317.

Anderson, J., et al. (2014). The culture of disbelief: an ethnographic approach to understanding an undertheorised concept in the UK asylum system. Oxford: Refugee Studies Centre, Oxford Department of International Development https://www.rsc.ox.ac.uk/files/files-1/wp102-culture-of-disbelief-(2014).pdf. Accessed 06.19.2017.

Balch, A. (2016). Immigration and the state: fear, greed and hospitality. UK: Palgrave Macmillan.

Beaverstock, J. (2005). Transnational elites in the city: British highly-skilled inter-company transferees in New York city's financial district. Journal of Ethnic and Migration Studies, 31(2), 245-268.

Bentley, G., \& Pugalis, L. (2013). New directions in economic development: localist policy discourses and the Localism Act. Local Economy, 25(3), 257-274.

Birrell, D. (2009). The impact of devolution on social policy. Bristol: Bristol Policy Press.

Braun, V., \& Clarke, V. (2006). Using thematic analysis in psychology. Qualitative Research in Psychology, 3, $77-101$.

Casey, L. (2016). The Casey Review: a review into opportunity and integration. London: Department for Communities and Local Government http://dera.ioe.ac.uk/27950/1/The_Casey_Review.pdf. Accessed 01.30.2017.

Cheung, S. Y., \& Heath, A. F. (2007). Nice work if you can get it: ethnic penalties in Great Britain. In A. F. Heath \& S. Y. Cheung (Eds.), Unequal chances: ethnic minorities in Western labour markets, Proceedings of the British Academy (pp. 507-550). Oxford: Oxford University Press.

Christie, C. (2011). Commission on the future delivery of public services. Edinburgh: Scottish Government http://www.gov.scot/Resource/Doc/352649/0118638.pdf. Accessed 06.22.2017. 
Clarke, N., \& Cochrane, A. (2013). Geographies and politics of localism: the localism of the United Kingdom's coalition government. Political Geography, 34, 10-23.

Collett, E., \& Petrovic, M. (2014). The future of immigrant integration in Europe: mainstreaming approaches for inclusion. Washington, DC: Migration Policy Institute http://www.migrationpolicy. org/research/future-immigrant-integration-europe-mainstreaming-approaches-inclusion. Accessed 06.22.2017.

Crul, M., \& Schneider, J. (2010). Comparative integration context theory: participation and belonging in new diverse European cities. Ethnic and Racial Studies, 337, 1249-1268.

Curtice, J. (2006). A stronger or weaker union? Public reactions to asymmetric devolution in the United Kingdom. Publius: The Journal of Federalism, 36(1), 95-113.

DCLG. (2011). A plain English guide to the Localism Act. London: Department for Communities and Local Government https://www.gov.uk/government/uploads/system/uploads/attachment_data/file/5959 /1896534.pdf. Accessed 06.22.2017.

DCLG. (2012). Creating the conditions for integration. London: Department for Communities and Local Government.

Gebhardt, D. (2016). When the state takes over: civic integration programmes and the role of cities in immigrant integration. Journal of Ethnic and Migration Studies, 42(5), 742-758.

Hansen, R. (2000). Citizenship and immigration in post-war Britain: the institutional origins of a multicultural nation. Oxford: Oxford University Press.

Heath, A., McMahon, D., \& Roberts, J. (2000). Ethnic differences in the labour market: a comparison of the samples of anonymized records and Labour Force Survey. Journal of the Royal Statistical Society: Series A Statistics in Society, 163(3), 303-339.

Hepburn, E. (2015). New Scots and migration in the Scottish independence referendum. Scottish Affairs, 24(4), 409-418.

HOC House of Commons. (2011). The Localism Act (2011). London: House of Commons.

Jenkins, R. (1967). Essays and speeches by Roy Jenkins. London: Collins.

Jivraj, S. (2012). How has ethnic diversity grown 1991-2001-(2011)? Manchester: Centre on Dynamics of Ethnicity CoDE, University of Manchester http://www.ethnicity.ac.uk/medialibrary/briefingsupdated/howcan-we-count-immigration-and-integration.pdf. Accessed 08.07. 2014.

Joppke, C. (1998). Challenge to the nation-state: immigration in Western Europe and the United States. Oxford: Oxford University Press.

Jupp, V. (2006). The Sage dictionary of social research methods. London: Sage.

Katwala, S., et al. (2017). Integration: from national rhetoric to local reality, how the new mayors for cityregions can help get integration right at local level. London: British Future http://www.britishfuture. org/wp-content/uploads/(2017)/04/Mayors-and-integration-report.FINAL_.pdf. Accessed 06.22.2017.

Kvale, S., \& Brinkmann, S. (2008). InterViews: learning the craft of qualitative research interviewing (2nd edn.). Los Angeles: SAGE Publications, Inc.

Law, A., \& Mooney, G. (2012). Competitive nationalism: state, class, and the forms of capital in devolved Scotland. Environment and Planning, 30(1), 62-77.

Lessard-Phillips, L. (2017). Perspectives on the adaptations of immigrants in Britain [Data Collection]. Colchester: UK Data Archive. https://doi.org/10.5255/UKDA-SN-852602.

Midwinter, A. (1999). The Barnett Formula and public spending in Scotland: policy and practice. Scottish Affairs, 28(1), 83-92.

Miles, R. (1993). Racism after race relations. London: Routledge.

Mitchell, J. (1998). What could a Scottish parliament do? Regional and Federal Studies, 8(1), 68-85.

Mooney, G., \& Williams, C. (2006). Forging new 'ways of life'? Social policy and nation building in devolved Scotland and Wales. Critical Social Policy, 26(3), 608-629.

Morris, L. (2002). Managing migration: civic stratification and Migrants' rights. London: Routledge.

Mulvey, G. (2015). Refugee integration policy: the effects of UK policy-making on refugees in Scotland. Journal of Social Policy, 44(2), 357-375.

Mulvey, G. (2018). Social citizenship, social policy and refugee integration: a case of policy divergence in Scotland? Journal of Social Policy, 47(1), 161-178.

Office for National Statistics. (2013). (2011) Census analysis, immigration patterns of non-UK born populations in England and Wales in (2011). London: ONS http://www.ons.gov.uk/ons/rel/census/(2011)census-analysis/immigration-patterns-and-characteristics-of-non-uk-born-population-groups-in-englandand-wales/index.html. Accessed 07.05.2015.

Ruhs, M., \& Anderson, B. (Eds.). (2010). Who needs migrant workers? Labour shortages, immigration and public policy. Oxford: Oxford University Press. 
Saggar, S., \& Somerville, W. (2012). Building a British model of integration in an era of immigration: policy lessons for government. Washington, DC: Migration Policy Institute.

Scholten, P., Collett, E., \& Petrovic, M. (2017). Mainstreaming migrant integration? A critical analysis of a new trend in integration governance. International Review of Administrative Sciences, 83(2), 283-302.

Scottish Government. (2013). New Scots: integrating refugees in Scotland's communities. Edinburgh: Scottish Government http://www.gov.scot/Publications/(2013)/12/4581/downloads\#res439604. Accessed 06.22.2017.

Scottish Government. (2016). Post study work steering group report of final recommendations. Edinburgh: Scottish Government http://www.gov.scot/Publications/(2016)/03/5056. Accessed 06.22.2017.

Solomos, J. (1989). Race and racism in contemporary Britain. London: Palgrave.

Spencer, S. (2011). The migration debate. Bristol: Policy Press.

Squire, V. (2009). The exclusionary politics of asylum. London: Routledge.

Stewart, E., \& Shaffer, M. (2015). Moving on? Dispersal policy, onward migration and integration of refugees in the UK. Glasgow: University of Strathclyde.

Vargas-Silva, C., \& Markaki, Y. (2017). Briefing: long-term international migration flows to and from the UK 6th revision. Oxford: The Migration Observatory http://www.migrationobservatory.ox.ac.uk/wpcontent/uploads/(2016)/04/Briefing-LTIM_FLows_UK-2.pdf. Accessed 06.22.2017. 